\title{
Role of Circulating Serum Apelin-13 Levels in Glomerulonephritis: A Pilot Study
}

\author{
Yasemin Coskun Yavuz ${ }^{*}$, Can Sevinc ${ }^{1}$, Mustafa Saygin Deniz ${ }^{2}$, Serkan Yavuz ${ }^{2}$, Orcun Altunoren ${ }^{2}$, \\ Ahmet Celik ${ }^{2}$, Recep Demirci ${ }^{3}$, Hayriye Sayarlioglu ${ }^{4}$ and Ekrem Dogan ${ }^{5}$
}

${ }^{1}$ Erzurum Regional Research and Training Hospital, Internal Medicine, Department of Nephrology, Erzurum, Turkey

${ }^{2}$ Kahramanmaras Sutcu Imam University, Department of Internal Medicine, Kahramanmaras, Turkey

${ }^{3}$ Kanuni Sultan Suleyman Research and Training Hospital, Internal Medicine, Department of Nephrology, Istanbul, Turkey

${ }^{4}$ Ondokuz Mayıs University, Internal Medicine, Department of Nephrology, Samsun, Turkey

${ }^{5}$ Selahattin Eyyubi University, Internal Medicine, Department of Nephrology, Diyarbakir, Turkey

*Corresponding author: Yasemin Coskun Yavuz, Erzurum Regional Research and Training Hospital, Department of Nephrology, Erzurum, Turkey, Tel: 904422325307; E-mail: yasemincoskun@yahoo.com

Received date: November 11, 2015; Accepted date: November 16, 2015; Published date: November 23, 2015

Citation: Yavuz YC, Sevinc C, Deniz MS, Yavuz S, Altunoren O, et al. (2015) Role of Circulating Serum Apelin-13 Levels in Glomerulonephritis: A Pilot Study. J Clin Exp Nephrol 1: 2. DOI: 10.21767/2472-5056.100002

Copyright: (C) 2015 Yavuz YC, et al. This is an open-access article distributed under the terms of the Creative Commons Attribution License, which permits unrestricted use, distribution, and reproduction in any medium, provided the original author and source are credited.

\section{Abstract}

Introduction: Apelin is secreted from white fat tissue, and it is an adipokine. Increased apelin levels were observed in kidney biopsy of rats formed nephropathy throughout glomerular basal membrane. Thus, the purpose of this study was to evaluate the difference of apelin-13 levels in patients with glomerulonephritis and healthy patients.

Materials and methods: This study included 107 subjects, comprising 53 glomerulonephritis patients that were newly diagnosed and under continuing treatment and 54 healthy individual used as control group. Demographic data and laboratory findings were recorded from hospital information file system. Apelin-13 levels were compared between the patient and control group. Furthermore, relationship between apelin-13 levels and arterial blood pressure, mass body index, proteinuria, albumin, creatinine was evaluated in the patient group.

Results: Apelin-13 level exhibited averages of $1863 \pm 1783$ $\mathrm{pg} / \mathrm{ml}$ in patient group and $2392 \pm 1846 \mathrm{pg} / \mathrm{ml}$ in control group. No significant differences were found between groups. Apelin levels between the glomerulonephritis patients with proteinuria and glomerulonephritis patients without proteinuria were compared, patients with proteinuria had $1784 \pm 1756 \mathrm{pg} / \mathrm{ml}$ and patients without proteinuria had $2274 \pm 1896 \mathrm{pg} / \mathrm{ml}$ apelin-13. Between the two groups there was not a significant difference.

Discussion: In summary, our findings indicate that apelin-13 levels showed no significant difference between the patients with glomerulonephritis and healthy control group.

\section{Introduction}

Apelin is a new peptide identified as the endogenous ligand of the $\mathrm{G}$ protein-coupled receptor, APJ. Apelin-related peptides were first isolated from bovine stomach extracts as soluble factors able to increase extracellular acidification rate and inhibitcAMPproduction in hamster ovary cells transfected with APJCDNA[1]. Apelin is secreted from brain, placenta, lungs, heart, kidneys also from the veins of coronary artery, saphenous vein, kidneys and adrenal gland [2]. Apelin is secreted as preproapelin, that has the sequence of 77 amino acids, preproapelin is then fragmented by protease and apelin will be named as Apelin-13, Apelin-17 andApelin-36, depending on the number of amino acids it contains. Apelin-36 and apelin-13 represent the predominant and most active isoforms. Apelins show effect with the different affinity attachments to apelin (APJ) receptor. APJ receptor is found in 1993 for the first time, and named as angiotensin-II receptor-like 1 (AGTRL1) due to the resemblance to Angiotensin II type $1[3,4]$. That apelin has a beneficial effect of on renal disease is also suggested by several studies. For example, apelin has been found to lower blood pressure in the two-kidney-one-clip hypertension rat model through its effect on vascular relaxation [5]. Apelin has also been observed to protect cells at a histopathological level in a rat model of renal ischaemia and reperfusion injury [6]. Furthermore, subcutaneous injection of apelin-13 reduces glomerular hypertrophy and renal inflammation in Ove26 mice, a model of type 1 diabetes. Also, reduced proteinuria is observed with injected apelin in rats with caused diabetic nephropathy [7]. However, the mechanisms by which apelin-13 protects against renal diseases are still unclear. Also in several studies, it was found that the association between proteinuria and nephrotic syndrome with renal tissue levels of apelin-13, but there is no clinical studies that have measured the levels of serum apelin-13 in glomerulonephritis. In this study we aim to 
observe the circulating serum apelin-13 levels in patients with glomerulonephritis by comparing with healty subjects.

\section{Materials and Methods}

The study protocol was approved by the Kahramanmaras Sutcu Imam University Local Ethics Committee (protocol 1205/14). 53 glomerulonephritis patients that were newly diagnosed and under continuing treatment was used in our study. Demographic data and the levels of creatinine, albumin, urinalysis and spot urine protein/creatinine ratios of these patients were recorded from hospital information file system. The patients' BMI values were calculated using the formula weight $(\mathrm{kg}) /$ height $(\mathrm{m})^{2}$. Body surface area was calculated using the formula $0.007184 \times$ height $(\mathrm{cm})^{0.725} \times$ weight $(\mathrm{kg})^{0.425}$. Blood pressure was measured using a calibrated aneroid sphygmomanometer that had a cuff width and balloon diameter suitable for each patient, in accordance with the World Health Organization's (WHO) measurement criteria. Patients' body mass indexes and arterial blood pressures were measured and recorded. 54 healthy individual was taken to the study as a control group. As a control group; without acute or chronic disease known, non-regular drug use history for any reason, ages ranging from 19 to 65 , GFR values $\geq 90 \mathrm{ml} / \mathrm{min} / 1.73 \mathrm{~m}^{2}$ with, without hematuria and proteinuria, BMI value $<35 \mathrm{~kg} / \mathrm{m}^{2}$, 10 men, 26 women out of a total of 36 healthy volunteers was created. Upon receiving the informed consent from both groups, $3 \mathrm{cc}(\mathrm{ml})$ blood was collected. The bloods were centrifuged and serum was separated and stored at $80^{\circ} \mathrm{C}$. Apelin-13 (USCN Life Science Inc.) levels of these serums were measured with ELISA (enzymelinked immunosorbent assay) method and automated ELISA microplate reader (Thermo Scientific, Finland). Apelin-13 (USCN Life Science Inc.) levels of these serums were calculated as the units of $\mathrm{pg} / \mathrm{ml}$ with the computer program Skanlt for Multiscan FC 2.5.1. Sensitivity was $37.2 \mathrm{pg} / \mathrm{ml}$ and detection range was $98.8-8000 \mathrm{pg} / \mathrm{ml}$. Relationship between apelin-13 levels and mean arterial pressure (MAP), body mass index (BMI), proteinuria, albumin, creatinine was evaluated in the patient group. Apelin-13 levels were compared between the patient group and healthy control group.

\section{Statistical analysis}

Statistical analysis was performed by the SPSS program for Windows, version 17.0. Continuous variables are presented as mean \pm SD, and categorical variables are presented as absolute numbers and percentage. Data were checked for normality before statistical analysis. Comparisons between groups (patients versus controls) were by Student's t-test (for data that were normally distribution). Correlations between serum apelin-13 level and continuous variables were determined using Pearson correlation $\mathrm{p}$-value less than 0.05 were taken to indicate a significant difference for all statistical tests.

\section{Results}

The patient group was consisted of 31 (58.5\%) male and 22 (41.5\%) female with an average age of 38.116 .9 , average BMI of $27.5 \pm 5.3 \mathrm{~kg} / \mathrm{m}^{2}$, average MAP value $90.6 \pm 6 \mathrm{mmHg}$, average creatinine level $1.1 \pm 0.6 \mathrm{mg} / \mathrm{dl}$, average albumin level $4.05 \pm 0.6$ $\mathrm{g} / \mathrm{dl}$, average CRP level $7.1 \pm 8.1 \mathrm{mg} / \mathrm{dl}$ and the ratio of spot urine protein/creatinine is $1.5 \pm 1.9 \mathrm{mg} / \mathrm{dl}$. Control group was consisted of the total 54 healthy individuals; 18 males and 36 females with the average age $40.7 \pm 13.6$, average BMI 27.45 .4 $\mathrm{kg} / \mathrm{m}^{2}$, average MAP $90.9 \pm 5.9 \mathrm{mmHg}$, average albumin level 4.5 $\pm 0.2 \mathrm{~g} / \mathrm{dl}$, average creatinine level $0.67 \pm 0.13 \mathrm{mg} / \mathrm{dl}$. Similar values of BMI ( $p: 0.09)$, age (0.39) and MAP value $(p=0.47)$ were seen in the both group; meanwhile a significant lower albumin level was observed at the patient group $(p<0.001)$. Demographic and laboratuary values of the groups are shown in Table-1. 13 patients had hypertension and 40 patients did not. 40 (75.5\%) of 53 patients were receiving nonimmunosuppressive treatment. 32 of 53 patients had been received nonimmunosuppressive treatment. 13 patients showed no proteinuria in urine analysis, 6 patients had trace amount of proteinuria, 9 patients showed +1 and 23 patients showed +3 proteinuria. The most common 3 reasons, that were shown in the tissue analysis, were $\lg A$ nephropathy for 16 patients, membranous glomerulonephritis (MGN) for 10 patients and membranoproliferative glomerulonephritis (MPGN) for 9 patients. Apelin-13 levels were compared between the group of patients and control group. Average apelin-13 level was $1863 \pm$ $1783 \mathrm{pg} / \mathrm{ml}$ for patient group and average apelin-13 was $2392 \pm$ $1846 \mathrm{pg} / \mathrm{ml}$ for control group. A significant difference between the groups had not been seen $(p=0.13)$ (Table 2$)$. Apelin levels between the glomerulonephritis patients with proteinuria and glomerulonephritis patients without proteinuria were compared for any differences. Patients with proteinuria had $1784 \pm 1756$ $\mathrm{pg} / \mathrm{ml}$ and patients without proteinuria had $2274 \pm 1896 \mathrm{pg} / \mathrm{ml}$ apelin-13 $(p=0.43)$. The correlation between protein/creatinine ratio and apelin-13 level was checked via spot urine analysis in patient group of glomerulonephritis, there was no significant correlation ( $p=0.83, r=0.15)$. Also there was no significant correlation between apelin-13 levels and BMI ( $p=0.26, r=0.131)$, weight ( $p=0.28, r=0.198)$, albumin levels $(p=0.66, r=0.212)$ in the patient group. Apelin-13 levels were compared between immunosuppressive treated (average $1828 \pm 1798 \mathrm{pg} / \mathrm{ml}$ ) and untreated patients (average $1918 \pm 1802$ pg/ml). Apelin-13 levels were not significantly different between in two groups $(p=0.85)$.

Table 1: The demographic values of the patient and control group.

\begin{tabular}{|l|l|l|l|}
\hline & Patients $(\mathbf{n = 5 3})$ & Control $(\mathbf{n = 5 4 )}$ & p-value \\
\hline Age (years) & $38.1 \pm 16.9$ & $40.7 \pm 13.6$ & 0.39 \\
\hline Gender (M/F) & $31 / 22$ & $18 / 36$ & \\
\hline BMI (kg/m2) & $27.5 \pm 5.3$ & $27.4 \pm 5.4$ & \\
\hline MAP (mmHg) & $90.6 \pm 6$ & $90.9 \pm 5.9$ & 0.09 \\
\hline Creatinine (mg/dl) & $1.1 \pm 0.6$ & $0.67 \pm 0.13$ & \\
\hline Albumin (gr/dl) & $4.05 \pm 0.6$ & $4.5 \pm 0.2$ & $<0.001$ \\
\hline BMI: Body Mass Index; MAP: Mean Arterial Pressure & \\
\hline
\end{tabular}

Table 2: The Apelin-13 levels of patients and control group. 


\begin{tabular}{|c|c|c|c|}
\hline & Patient & Control & p-value \\
\hline$\underset{(\mathrm{pg} / \mathrm{ml})}{\text { Apelin }} \quad 13$ & $1863 \pm 1783$ & $2392 \pm 1846$ & 0.13 \\
\hline
\end{tabular}

\section{Discussion}

The distribution of apelin and apelin receptor APJ has been found in kidneys along with most tissues [1]. Intermediate level of preproapelin has been found in kidney, heart, lungs and mammal gland, mostly preproapelin is seen in central nerve system and placenta [9]. Apelin receptor APJ is shown to be expressed in the kidneys of rats and human. APJ receptor expression has been found mostly at the inside of outer medulla along vasa recta and leastly at outside of outer medulla and cortex [10]. Increased Apelin and APJ mRNA levels are observed in the rats, that are unilateral fibrosis caused by ureteral obstruction [11]. Increased apelin levels are found along glomerular basal membrane in the rats with adriamycin induced nephrotic syndrome [7]. Decreased APJ receptor levels are observed upon deliver of the apelin in glomeruli and kidney veins of the rats with diabetic nephropathy [12]. The effect of Apelin APJ system on tissue fibrosis and progression is shown at liver fibrosis [13]. The effect of Apelin APJ system is shown to result in decrease of fibrosis against angiotensin 2 at heart and kidney fibrosis [14]. Rats formed renal fibrosis with one tied ureter, the decreased effect of ARB on fibrosis has been found to be increased with apelin APJ system and shown as increased levels in the side with tied ureter. All antifibrotic effect of ARBs are observed to be decreased with the deliver of antagonist of APJ receptor. These results are thought to be a hope for decreasing fibrosis with apelin like RAAS inhibitors $[10,11]$. A study with rats formed diabetic nephropathy, upon delivery of apelin-13; no significant change in the weight and serum glucose levels; decreased glomerular hypertrophy, no significant change in albuminuria for the first 3 months but at the end of 6 months with the injection of apelin-13 significant decrease in albuminuria has been observed. Also; reduced activation of angII, AT1 receptor with apelin has not been observed. Therefore, it has been thought antioxidant system activation is the reason for reduced proteinuria. In pathologic examinations, the number of podocytes has remained the same but reduced proteinuria via epithelial cells of the proximal tubule are found [15]. Unlike the existing studies we investigated the serum apelin-13 levels in glomrulonephritis, not in the renal tissue. In our study, serum apelin-13 levels showed no significant difference between the patients with glomerulonephritis and healthy control group. We did not find such a study in the literature about association between serum apelin-13 levels and glomerlonephritis. Also unlike the present studies we couldn't find a significant correlation between serum apelin-13 levels with proteinuria. In addition, in patients with glomerulonephritis we did not find significant differences in serum apelin-13 levels between among those taking the immunosuppressive therapy and not taking. In animal experiments, apelin is found increased at fibrosis formed kidneys and also increased apelin is seen along glomerular basal membrane in rats with nephrotic syndrome. If we had done renal biopsy, we could have found a different apelin level in tissues between glomerulonephritis patients and control group but in the serum we did not see a significant difference. Due to the fact of ethical reasons, it seems hard to make a clinical study with renal biopsy in control group. On the other hand, the low number of patients in our study may have affected the results. For now, as a conclusion; there was no significant difference between glomerulonephritis patients and control group in our study.

\section{References}

1. Boucher (2005) Apelin, a Newly Identified Adipokine Up-Regulated by Insulin and Obesity. Endocrinology 146: 1764-1771.

2. Kawamata $Y$, Habata Y, Fukusumi S, Hosoya M, Fujii R, et al. (2001) Molecular properties of apelin: tissue distribution and receptor binding. Biochim Biophys Acta 1538: 162-171.

3. Foldes G, Horkay F, Szokodi I, Vuolteenaho O, Ilves M, et al. (2003) Circulating and cardiac levels of apelin, the novel ligand of the orphan receptor APJ, in patients with heart failure. Biochem Biophys Res Commun 308: 480-485.

4. Kälin RE, Kretz MP, Meyer AM, Kispert A, Heppner FL, et al. (2007) Paracrine and autocrine mechanisms of apelin signaling govern embryonic and tumor angiogenesis. Dev Biol 305: 599-614.

5. Soltani Hekmat A, Najafipour H, Nekooian AA, Esmaeli-Mahani S, Javanmardi K (2011) Cardiovascular responses to apelin in twokidney-one-clip hypertensive rats and its receptor expression in ischemic and non-ischemic kidneys. Regul Pept 172: 62-68.

6. Sagiroglu T, Torun N, Yagci M, Yalta T, Sagiroglu G, et al. (2012) Effects of apelin and leptin on renal functions following renal ischemia/reperfusion: An experimental study. Exp Ther Med 3: 908-914.

7. Day RT, Cavaglieri RC, Feliers D (2013) Apelin retards the progression of diabetic nephropathy. Am J Physiol Renal Physiol 304: 788-800.

8. O'Dowd BF, Heiber M, Chan A, Heng H, Tsui LC, et al. (1993) A human gene that shows identity with the gene encoding the angiotensin receptor is located on chromosome 11. Gene 136: $355-360$.

9. Castan-Laurell I, Boucher J, Dray C, Daviaud D, Guign'e C, et al. (2005) Apelin, a novel adipokine over-produced in obesity: Friend or foe? Molecular and Cellular Endocrinology 245: 7-9.

10. Hus-Citharel A, Bouby N, Frugière A, Bodineau L, Gasc JM, et al. (2008) Effect of apelin on glomerular hemodynamic function in the rat kidney. Kidney Int 74: 486-494.

11. Nishida M, Okumura Y, Oka T, Toiy-ama K, Ozawa S, et al. (2012) The role of apelin on the alleviative effect of angiotensin receptor blocker in unilateral ureteral obstruction-induced renal fibrosis. Nephron Extra 2: 39-47.

12. Bo Y, Yuan L (2012) Glomerular expression of apelin and its association with proteinuria. Indian J Pediatr 79: 1028-1032.

13. Fukushima $\mathrm{H}$, Kobayashi $\mathrm{N}$, Takeshima $\mathrm{H}$, Koguchi $\mathrm{W}$, Ishimitsu $T$ (2010) Effects of olmesartan on Apelin/APJ and Akt/eNOS pathway in Dahl rats with end-stage heart failure. J Cardiovasc Pharmacol 55: 83-88.

14. Nishida M, Okumura Y, Oka T, Toiy-ama K, Ozawa S, et al. (2012) The role of apelin on the alleviative effect of angiotensin receptor blocker in unilateral ureteral obstruction-induced renal fibrosis. Nephron Extra 2: 39-47. 
15. Pchejetski D, Foussal C, Alfarano C, Lairez O, Calise D, et al. (2012) Apelin prevents cardiac fibroblast activation and collagen production through inhibition of sphingosine kinase 1. Eur Heart J 33: 2360-2369. 